\title{
The power of musical sound and its implications for primary education in South Africa: An experiential discussion
}

\author{
CAUERBACH ${ }^{l}$ AND A DELPORT ${ }^{2}$
}

\begin{abstract}
In this article, the power of musical sound and its transformative effects on human beings are explored, as perceived since ancient times and discussed in recent literature. An evolving research project is then reviewed, with a group of primary school children from disadvantaged backgrounds with no prior formal musical training.

In essence, the aim of the study in progress is to determine how musical sound can be used to facilitate mindfulness, develop wholeness and facilitate the holistic growth of young South African learners, especially those from deprived backgrounds.

Initial findings suggest that when musical sound experiences are included in everyday education of young learners, there are moments of joy, spontaneity, a sense of unity and well-being. The listening capacity of the children in the group has refined and performance levels at school have improved.
\end{abstract}

Keywords: Musical sound, music education, mindfulness, healing, wholeness, South Africa

\section{Introduction}

In his Phaedrus (see Jowett, 1999, p. 805), Plato's dialogue of Socrates (from 400 years BC) likens the soul to a chariot with a charioteer and two horses. The divine soul, according to Plato, has a noble charioteer and two noble horses. This allows 'the gods' to soar aloft, as they have well-ordered chariots. The human chariot, on the other hand, comprises a pair of horses, one of noble breed and one ignoble. Consequently, the human chariot is more difficult to manage, and often ends up sinking to the ground. Hence, learning to 'manage the soul', according to Plato, is the challenge of the human embodiment. Before the ignoble

Christina Auerbach works as a healing therapist and through teaching and her healing practice, has spent many years exploring the power of pure sound and beneficial effects of singing and chant. She is currently working on a master of education degree on the power of sound and its implications on the education of primary school children in South Africa through Nelson Mandela Metropolitan University, Port Elizabeth, Eastern Cape, South Africa. christina@rainman.co.za

Alette Delport is Associate Professor and Director of the School for Initial Teacher Education, Faculty of Education, Nelson Mandela Metropolitan University, in Port Elizabeth. She is involved in research projects focussing on educational transformation, as well as arts and music education for the nonspecialist teacher. Aletta.Delport@nmmu.ac.za 
horse will come under the dominion of a disciplined and reasonable mind, titanic struggles may take place between wilful wild desires and the dictates of clarity and reason. Plato thus held that, in order to soar upward, the human soul requires mindfulness and connection with that which is 'best in the world' (Jowett, 1999, p. 808).

In the twentieth century, world renowned psychiatrist and psychotherapist Carl Jung asserted that 'sickness of the soul' was caused by the sense of a meaningless life. Jung contended that society did not comprehend the full extent and full import of 'the sickness of the soul' (see Hassed, 2012). Today, in the $21^{\text {st }}$ century, incidences of mental ailments such as depression are on a steady rise, affecting many people in all walks of life. The need for individuals to experience life as meaningful is nowadays seen as a critical requisite for good physical and psychological health. Hence, regular physical exercise, good nutrition, connectedness, favourable environments, proper education, and an ability to manage stress, are generally regarded as key determinants of healthy living (Hassed, 2008). Hassed, however, highlights 'spirituality' in particular, as giving specific meaning to life, hence its potential to heal the 'sickness of the soul'. Hassed's postulation (2008) subsequently led medical educators at Monash University in Australia to include 'mindfulness training' in their curriculum for general practice, as it has been shown to assist medical trainees integrating complex medical theory through its calming and illuminating effects. Stanford University in California, United States of America, also has a Centre for Compassion and Altruism Research and Education that offers mindfulness training.

'Mindfulness' in this context is defined as

$$
\begin{aligned}
& \text { the awareness that emerges through paying attention on purpose, in the present } \\
& \text { moment, and non-judgementally to the unfolding of experience, moment to moment } \\
& \text { (Kabat-Zinn, 2003, cited in Feldman et al., 2007, p. 177). }
\end{aligned}
$$

In essence, mindfulness thus implies connecting with one's senses. Unfortunately, presentday society is characterised by an overload of sensory stimulation and instant gratification. Moreover, due to technological and multimedia advances, sensations are artificially heightened, subjecting individuals to emotional manipulation (Menuhin \& Davis, 2000). The ability to listen is particularly compromised. Berendt (1983, p. 139) for example, argues that nowadays, people "use their ears only when their eyes are insufficient". Goldman (1993, p. 81) accordingly distinguishes between 'hearing' and 'listening', defining hearing as a passive experience, whereas listening implies active, focussed immersion. Listening thus requires a measure of quiet in the head and a presence of mind that will allow connection with sounds picked up by one's senses. Listening with full attention enables us to be fully present in the moment, connecting with what is really happening. It allows us the possibility of responding fully to what is present, rather than filtering our response through a veil of belief systems and conditioning.

The ability to listen naturally and optimally can be restored through simple exercises of sounding and listening. Musical sound and toning train the ear and develop listening skills. Listening to musical sounds thus facilitates 'mindfulness', as it enables attentive awareness, and generous, indulgent engagement with the present moment (Kabat-Zinn, 2003, cited in Feldman 2007, p. 177).

The power of sound to influence thoughts and actions has been understood since ancient times (Bicknell, 2010). Almost all ancient cultures and indigenous peoples regarded sound as the generative force which created the universe. Cutting across historical, religious and 
political lines, Egyptians, Hebrews, Native Americans, Celts, Chinese and Christians all have spoken of sound as a divine principle (Tame, 1984, p. 206). The gospel of John starts: 'In the beginning was the Word, and the word was with God and the Word was God'. The Vedic Scriptures refer to this word or sound as OM, calling it the Pranawa Shabda or original sound. In Ancient Egypt it was 'the word of words', and to the Pythagoreans of Greece, sound was the 'music of the spheres'. Ihde (2007, p. 3) accordingly holds that the "beginning of man is in the midst of word. And the centre of word is in breath and sound, in listening and speaking".

In Ancient China, three thousand years before Christ, great care was thus taken to ensure that the fundamental tone, called buang chung or 'divine will', was in perfect tune as the earthly rendering of the word. It was assumed that any deviation would lead to eventual instability in society. The major effect of musical sound in particular, was understood to be its moral influence. The Chinese emperors therefore believed that they needed to control musical sound. Emperor Shun would visit all the local areas under his care in the second month of every year to ensure that the tuning of the instruments was correct. Such practices continued for four and a half millennia until the Chi'ng dynasty of 1644 (Tame, 1984, p. 40, 41).

In the $18^{\text {th }}$ century, Ernst Chladne (1756-1827, cited in Campbell, 1997) finally managed to demonstrate the effect of musical sound vibration on matter. When a violin bow was drawn over the edge of the plate and a pure sound created, sand grains or poppy seeds loosely spread over a flat plate took on symmetrical forms. Berendt (1983, p. 91) describes this phenomenon as "sound calling the particles to order". During the 1960s, the study on the effects of vibration on matter was taken further by Hans Jenny and referred to as 'cymatics'. In his introduction to the book Cymatics (Jenny, 2001), the publisher (Volk, 2001, p. 8) describes how through the use of a tonoscope, Jenny made visible spoken sound and demonstrated the different patterns created by different vowel sounds. Jenny captured extraordinary images that mirrored biological forms, created through sound vibration in liquid glycerine photographically. For example, one image was of a snake-like form, stripped down to its vertebrae, slowly undulating on the screen. Other images also resembled biological forms and natural processes such as flowers, intricate geometric shapes and honeycomb (Jenny, 2004). Volk (2001, p.8) thus argues that Jenny's experiments revealed 'the hidden nature of creation' and the very principle through which matter coalesces into form.

Similarly powerful are the subtle vibrations of musical sound produced by the human voice. Chant, by its very nature, consists of prolonged vowel sounds. Since ancient times, sacred traditions throughout the world have thus been using chant to instil a sense of presence and connectedness (Goldman, 2002; Campbell, 1997; Le Mee, 1994). D’Angelo (2000, p. 19) subsequently believes that the act of chanting enhances integration of 'body, mind and spirit'. It stimulates, purifies and balances the energies that generate 'wholeness'.

Past civilisations clearly held music sacred and it consequently gave man a sense of beauty and perfection that could be aspired to. Beauty and truth are combined in music, and as such, music cultivates "greater maturity, awareness and equilibrium in our civilization" (Menuhin \& Davis, 2001, p. 43).

In recent years, interest in the power of musical sound re-emerged. In 1997, Campbell proposed the so-called Mozart Effect, suggesting that when one listens to Wolfgang Amadeus Mozart's (1756 - 1791) music, brainwaves are slowed down and equalised. Since beta waves subsequently change to alpha waves, a heightened state of calm and awareness is experienced 
by the listener. The respirations also deepen and slow down. The immune system is strengthened and digestion stimulated. Memory is also strengthened and the ability to learn is heightened. Campbell (1997) furthermore held that music can change one's perception of space, since one's immediate environment is experienced as more spacious, lighter, elegant, efficient and ordered. Ultimately, stress is reduced and productivity increased.

Although initially met with scepticism, Campbell's postulations (1997) have since been supported and expanded by numerous recent interdisciplinary research studies, confirming the beneficial impacts of musical encounters on human beings (see Kokotsaki \& Hallam, 2011; Leeds, 2010). Some of these findings are as follows:

- Costa-Giomi (1999) found that engagement with music improves self-esteem.

- Catterall and Rauscher (2008) detected gains in visual-spatial intelligence of learners who engaged with music (see Kokotsaki \& Hallam, 2011).

- Southgate and Roscigno (2009) as well as Anvari et al. (2002), found that music involvement leads to increased reading ability. It also improves phonemic awareness and spelling abilities (Overy 2003, 2000).

- Music encounters improve mathematical performance (Southgate \& Roscigno, 2009; Cheek \& Smith, 1999).

- Music also improves verbal memory (Ho, Cheung \& Chan, 2003), as well as auditory and audio-visual processing (Musacchia et al., 2007).

- Ings, Jones and Randell (2000, cited in Kokotsaki \& Hallam, 2011) in addition allude to music's social benefits, arguing that group music activities enhance awareness of others and improve social skills. Music enables self-expression and builds confidence in performance. It also improves group work, hence improving social inclusion.

- Ultimately, Wise, Hartmann and Fisher (1992) conclude that involvement in music cultivates mental well-being, good health and improved quality of life.

Despite music's evident multi-faceted and multi-layered benefits as outlined above, Menuhin and Davis (2007) strongly believe that at present, music has largely lost this curative and remedial role in society. Instead, it has become "part of the ubiquitous process of exploitation" associated with neo-liberal societies (Menuhin \& Davis, 2000, p. 271). General education today is thus characterised by a pre-occupation with 'intelligence', where 'aptitudes' are measured largely in terms of reading, writing and computer literacy competence (Campbell, 1997, p. 43). Rationality supersedes creativity and sensitivity, with linear leftbrained thinking being emphasised at the expense of development of listening and speaking skills.

Campbell (1997) subsequently warns that deficient listening ability may hamper the development of learners' higher-level learning skills. School education in the $21^{\text {st }}$ century should be conceived as more than mere accumulation of knowledge. It should also help children to think creatively and analytically, enabling them to become creative and innovative problem-solvers (Zuber-Skerritt, 2011). Education needs to be holistic, developing and involving all the senses so that auditory, visual and kinaesthetic learning styles are fully integrated and utilised.

In this regard, Maxine Greene (1995) holds that the arts should be central in school curricula especially since encounters with the arts have a unique power to release the imagination. Greene sees the role of the imagination as awakening and disclosing the ordinarily unseen, unheard and unexpected. She thus argues that to "conceive the arts in relation to curriculum, 
is to think of a deepening and expanding mode of tuning in" (Greene, 1995, p. 104). The arts are essential in developing brain pathways and connections that will produce society's much needed mathematicians, scientists and engineers, as well as developing well-rounded individuals who are socially, culturally and intellectually balanced (Wanyama, 2006).

Given that the majority of South African learners grow up in socially deprived contexts, the curative, transformative attributes of musical sound through meaningful music encounters clearly require further investigation. Our opinion is reinforced byJose Antonio Abreu's faith in music's potential to heal the emotional and spiritual depredations of poverty, especially in developing countries. Abreu, a contemporary Venezuelan economist and musician, sees poverty as not just the lack of a roof or bread but also as a spiritual dearth, a loneliness and lack of recognition (Tunstall, 2012). Abreu believes that,

\begin{abstract}
When arts education takes the place in our society that it deserves, we will have much less delinquency and violence, and much more motivation towards noble achievement. My struggle is for a society in which art is not just an aesthetic dimension of life. It is a primary instrument for the development of individuals and societies (cited in Tunstell, 2012, p. xi).
\end{abstract}

In 1975, Abreu founded a nationally-funded music education project in Venezuala, called $E l$ Sistema. Today, El Sistema is known particularly for rescuing many young children living in extremely impoverished circumstances from the environment of drug abuse and crime, into which they would likely otherwise have been drawn. At present, Venezuela has at least 31 symphony orchestras with 300 main nucleos or centres, each also having several orchestras. Currently 370,000 children attend El Sistema music schools around the country. These children are mostly from poor socio-economic backgrounds. Several research studies clearly link participation in the programme to improved school attendance and decline in juvenile delinquency. Hence, supported by the government, the El Sistema programme has since been introduced into the public school curriculum, aiming to be in every school by 2015 (Tunstell, 2012).

Our belief in the curative and transformative potential of meaningful music involvement is also reinforced by research conducted in first-world European countries. Studies for example conducted in Switzerland by Spychiger and Zulauf (1993, cited in Kokotsaki \& Hallam, 2011) indicated that increased music activities in the general classroom led to improved social cohesion within the class. According to Hanshumaker (1980, cited in Kokotsaki \& Hallam, 2011), this also resulted in greater self-reliance, better social adjustment and more positive attitudes, especially of low ability, disaffected learners. Most significantly, it was found that despite time being taken away from more academic lessons such as mathematics and English, to allow more time for music lessons, the children performed just as well, if not better, in the more academic subjects. This is an important finding since music, from our personal observations in schools, is often moved to the periphery of the school timetable to provide more time for reading, writing and arithmetic.

Menuhin and Davis (2000) accordingly argue that music education for all learners should also be justified for its extra-musical benefits such as its ability to enhance listening, intuition, criticality and open-mindedness. They furthermore hold that the way human beings perceive and process sounds is as important as the inherent quality of the sounds themselves. Yet teaching a child how to listen, pay attention to inflection and put sounds and speech into context, has largely been neglected by modern society. 


\section{The South African situation}

The attributes of music education, as discussed above, have also been acknowledged by policy makers in post-apartheid South Africa. At present, music education constitutes an integral component of the national school curriculum (known as the Curriculum and Assessment Policy Statement or CAPS), for the General Education and Training (GET) phase. This phase is subdivided into three phases, namely Foundation Phase (Grade R - 3), Intermediate Phase (Grade $4-6$ ) and Senior Phase (Grade 7 - 9), with 2 hours, 1.5 hours and 2 hours per week respectively allocated to creative arts in total (CAPS, 2014, p.6-7). However, despite policy endorsement, the quality of music education in most South African schools, and in particular schools in poverty-stricken areas, is questionable (Wentink, 2013; Browne, 2010; Vermeulen, 2009; Herbst, de Wet \& Rijsdijk, 2005). Generalist non-music specialist teachers, with little or no prior music training are expected to teach music at these underresourced schools. The musical training and background of these generalist teachers is completely inadequate (Wentink, 2013). Economic constraints furthermore lead school managers to reduce financial support for meaningful arts activities, creating a poorlyunderstood educational impoverishment (Tallal, 2013, cited in O'Brien, 2013).

In light of the above, further investigation into the influences of regular musical sound experiences on South African children from impoverished backgrounds seemed appropriate. In particular, we wanted to ascertain how regular involvement in music activities can cultivate a sense of wholeness and mindfulness, integrating 'body, mind and spirit', and thus helping these children to develop holistically, despite challenging social circumstances.

\section{Research methodology}

Greene (1995) believes that, when the arts are included in everyday experiences of young learners, this supports life, hope, the prospects of discovery, light, and ultimately wholeness. The dire need for young South African learners to be afforded an opportunity to transcend often impoverished circumstances, through attentive engagement with musical sound prompted our study. Converted into a research question, it is formulated as follows: How can musical sound be utilised to facilitate mindfulness, develop wholeness and thereby, facilitate the holistic growth of young South African learners, especially those from deprived social backgrounds? The aim of the study is thus to pilot and explore a particular approach to music education, in order to determine its applicability for similar contexts, not only in South Africa, but also elsewhere where young children grow up in poverty-stricken and hopeless conditions.

For the purposes of the study, Zuber-Skerritt's (2011) participatory action learning and action research (PALAR) was adopted as the most appropriate approach. PALAR combines research with learning and action. It has a transformative aim, as it strives to improve life by not only focussing on the generation of new knowledge but also its application in society. As such, PALAR is inclusive, holistic, always participative and collective (Zuber-Skerritt, 2011).

The empirical component of the study is conducted by Christina Auerbach, who has been working since February 2013 with a group of children between the ages of ten and fourteen after informed ethical consent was obtained from parents, care-givers and the children themselves. The programme is piloted at a community aftercare facility, located in the Southern Cape, South Africa. It is a non-profit organisation and entirely dependent on donations. The main objective is to improve the circumstances for young children living in local socio-economically deprived areas. 
This is done through the provision of a safe environment where children can be supervised, receive food, have fun and learn. Parents are also encouraged to become involved. The longterm goals are to keep children in school, encourage a culture of learning, broaden horizons and prevent children becoming involved in cycles of crime, early pregnancy, drug addiction and substance abuse. Working with the children's parents has been vital in achieving these objectives. At present, the aftercare facility is located in a house owned by a local church. The house has been divided into different areas for different classes and through the dedication of volunteer teachers, the children now have an educational and supportive structure to study in, rather than being on the street or in a house with no desk and little space or light.

\section{A sound awareness approach}

The study is premised on the transformative potential of musical sound, as discussed earlier in this article. As such, the music programme focuses primarily on facilitating awareness of and engagement with musical sound. In the programme, the aim is to enhance the development of the children's mindfulness. This happens through sounding and listening activities that enable them to connect with their senses, refining their auditory awareness. Each session begins with a 'falling still' exercise where the children are encouraged to follow a set of simple instructions in order to connect with their senses. These instructions include for example:

Sitting balanced and upright, become aware of the connection between your feet and the floor...

[Pause].

Feel the weight of the body on the chair...

[Pause].

Be aware of the touch of clothes on the skin and the movement of air on the face and hands...

[Pause]

Experience the sense of taste in the mouth...

[Pause]

Be aware of smell...

[Pause]

... and the movement of breath in and out of the body...

[Pause]

Listen to all the sounds in the room, extend that listening to sounds outside of the room and outside of the building...

This is then followed by a few moments of just sitting still. The children are also encouraged to practise this exercise and observe the effect it has on their being.

The following exercises focus on sounding and harmony. The children are encouraged to sound prolonged vowel sounds for the length of the breath on any note that feels comfortable. We then practise harmony work, collectively producing a major chord, sustaining the sound for the length of the breath.

TD, Special edition, 10(2), November 2014, pp. 1-11. 
A 'talking stick' is then passed from child to child, affording the stick-holder the opportunity to share whatever is on his or her mind. Everyone is encouraged to listen carefully to what is being said and only the one holding the stick is encouraged to speak. Response is entirely voluntary and the stick is simply passed on if someone does not want to say anything. According to the PALAR approach, the researcher is a co-participant, hence also taking a turn.

The next activity is in the form of finger exercises. The fingers are moved to different rhythms and rhymes, strengthening the finger muscles and improving co-ordination, in preparation for recorder work. The researcher and the children would each hold their hands in a loose fist, opening up the thumb pointing straight to the sky, closing back into a fist, moving thumbs pointing to each other in a horizontal position and then repeating with remaining digits while reciting certain words, such as:

We must do our exercises, exercises, exercises, we must do our exercises early in the morning. ${ }^{3}$

Another exercise involves placing all the fingertips and thumb tips together. One by one, they are then moved away and placed back together again. This exercise is also done to a rhyme, for example,

$$
\begin{aligned}
& \text { Tick-tock, tick-tock, } \\
& \text { rickety, pickety, clickety clock, } \\
& \text { the tick, the tock, the rock, the knock, } \\
& \text { put the keys inside the lock. }
\end{aligned}
$$

To the final part of the rhyme, the fingers are interlocked and gently stretched.

This is followed by a recorder session where the children are learning different note positions, learning to play simple songs and encouraged to recognise the notes they play on a music stave. The recorder was selected as the instrument of choice because it is light and easy to handle, develops finger co-ordination, lends itself to group playing and the researcher has a high level of competency with it. Percussion instruments and voice are also used to practise rhythms and to enrich the recorder sound.

The session concludes with a story with questions and answers in discussion format. The main aim of this activity is to encourage listening. At the same time, the children's thinking, learning and language skills in English, which is not their mother tongue, are also developed. Some of the stories have been selected from Stories for Thinking (Fisher, 1996). Care is also taken to share stories representative of a variety of cultures.

The questions are designed to challenge and extend the child's thinking in relation to the story in order to enhance the development of their deeper, philosophical thinking skills. The questions thus aim to stimulate thinking on issues such as truth, justice, friendship, service and courage, among others and children are encouraged to share their honest views. Care is taken to create a safe space conducive to philosophical thinking, hence the children are constantly reassured that there is no right or wrong answer. They are not allowed to criticise the views of others. They need to listen to others without interrupting. They are encouraged

3 These rhymes come from the Waldorf Steiner Education music syllabus. 
to exercise patience, waiting their turn to speak. They are also encouraged to justify their views and responses (Cassidy, 2009).

\section{Initial observations}

Although this research project is still in progress, our initial observations, feedback from caregivers and field notes reveal noticeable changes in the children in terms of academic performance, self-confidence and their enthusiasm.

At first, the exercise connecting with the senses was met with much giggling. Recent verbal feedback from the children has however been very positive as they relate these experiences to peacefulness, quiet and rest. As far as the sounding and harmony work are concerned, the general trend has been towards finer listening and more harmonious sounds. These are often met with general applause, indicating recognition of quality of sound. The children have taken to the finger exercises readily and willingly and love practising them. They are gradually developing music literacy and composing simple tunes with the notes they know, much to their enjoyment.

The person in charge of the aftercare facility has observed that the children's school marks have improved considerably and where children were failing last year they are now passing and passing well. The idea that they may in fact continue in school to complete Grade 12 is now a reality. A year ago it was not even in the children's consciousness.

Changes in their postures and how they carry themselves are also observable. When we first started working together they slouched and drooped over the table and were unable or unwilling to listen to each other. Both their listening and the posture have now improved, reflecting enthusiasm and eagerness to participate.

Initial observations clearly confirm research findings regarding music's benefits as discussed earlier in this article. These also endorse advocacy for more prominence of musical arts education in the national school curriculum. Focused exposure to and education in music and sound should clearly be available to all young South African learners

\section{Conclusion}

By consulting seminal literature, this article examined the power of sound, its nature and its potential transformative effects, especially for young children. It also reported on an existing research project in progress, exploring how sound can be utilised to facilitate mindfulness, wholeness, a sense of meaning and connectedness for young children.

The incorporation of a well-conceived musical arts programme, focusing in particular on enabling young learners to gain from the power of musical sound, will contribute in a unique manner towards achieving an education system that enhances the holistic development of the South African child.

\section{References}

Anvari, S.H., Trainor, L.J., Woodside, J. \& Levy B. Z. (2002) Relations among musical skills, phonological processing, and early reading ability in pre-school children. Journal of Experimental Child Psychology. 83. p.111-130. 
Berendt, J. E. (1983) The World is Sound. Rochester: Destiny Books.

Bicknell, J. (2010) Why music moves us. London: Palgrave Macmillan.

Browne, E. (2010) The implementation of the Arts and Culture learning area in the Intermediate Phase. Teacher experiences. Unpublished M Ed dissertation. Port Elizabeth: Nelson Mandela Metropolitan University.

Campbell, D. (1997) The Mozart Effect. London: Hodder \& Stoughton.

CAPS, 2014. Curriculum and Assessment Policy Statement Grades 10-12, Music. http://goo.gl/ThnXTU [accessed 12 November 2014]

Cassidy, C. (2009) Thinking children. The concept of 'child; from a philosophical perspective. London: Continuum International.

Cheek, J.M. \& L.R. Smith. (1999) Music training and mathematics achievement. Adolescence. 34. p.759-61.

Costa-Giomi, E. (1999) The effects of three years of piano instruction on children's cognitive development. Journal of Research in Music Education. 47 (5).p.198-212.

D'Angelo, J. (2000) Healing with the Voice. London: Thorsons.

Feldman, G., Hayes A., Kumar,S., Greeson, J. \& Laurer, J.E.J. (2007) Mindfulness and emotion regulation: the development and initial validation of the cognitive and affective mindfulness scale - Revised (CAMS-R). Journal of Psychopathology and Behavioural Assessment. 29. p.177-190.

Fisher, R. (1996) Stories for Thinking. Oxford: Nash Pollock Publishing.

Goldman, J. (1992) Healing Sounds. Rochester: Healing Arts Press.

Greene, M. (1995) Releasing the Imagination: Essays on education, the Arts and social change. San Francisco: Jossey-Bass.

Hassed, C. (2008) The essence of health: The 7 pillars of well-being. Sydney: Random House.

Hassed, C. (2012) Mindfulness: Why attention matters. Presentation given at workshop for health professionals through Lighthouse Resources, Brisbane, Australia.

Herbst, A., De Wet, J. \& Rijsdijk, S. (2005) A survey of music education in the primary schools of South Africa's Cape Peninsular. Journal of Research in Music Education. 53 (3). p. 260-283.

Ho, Y.C., Cheung, M.C. \& Chan. A.S. (2003) Music training improves verbal but not visual memory: cross sectional and longitudinal explorations in children. Neuropsychology. 17. p. $439-50$.

Ihde, D. (2007) Listening and voice. Phenomenologies of sound. Second edition. New York: State University of New York.

Jenny, H. (2001) Cymatics. Newmarket: Macromedia Publishing.

Jowett, B. (1999) The essential Plato, based on the Benjamin Jowett translation first published 1871, reprinted with introduction by Alain de Botton. New York: Quality Paperback Book Club. 
Kokotsaki, D. \& Hallam, S. (2011) The perceived benefits of participative music making for non-music university students: a comparison with music students. Music Education Research. 13 (2) p. 149-172.

Leeds, J. (2010) The Power of sound. Rochester: Healing Arts Press.

Le Mee, K. (1994) Chant: The origins, form, practice and healing power of Gregorian chant. New York: Bell Tower.

Musacchia, G., Sams, M. Skoe, E. \& Kraus. N. (2007) Musicians have enhanced sub-cortical auditory and audio-visual processing of speech and music. Proceedings of The National Academy of Sciences of the USA. 104 (40)p.15894-8.

Menuhin, Y. \& Davis, C.W. (2000) The Music of Man. London: Methuen Publishing.

O'Brien, J. (2013) Power of Art: Can music help treat children with attention disorders? BBC News, Washington. [Accessed: 5March 2013].

Overy, K. (2000) Dyslexia, temporal processing, and music: the potential of music as an early learning aid for dyslexic children. Psychology of Music. 28. p. 218-29.

Overy, K. (2003) Dyslexia and music: From timing deficits to musical intervention. Annals of the New York Academy of Science. 999. p. 497-505.

Southgate, D.E., \& Roscigno. V.J. (2009) The impact of music on childhood and adolescent achievement. Social Science Quarterly. 90 (1). p. 4-21.

Tame, D. (1984)The secret power of music. Rochester: Destiny Books.

Tunstall, T. (2012) Changing Lives. New York: W.W. Norton \& Company.

Vermeulen, D. (2009) Implementing music in an integrated Arts Curriculum for South African Primary Schools. Unpublished $\mathrm{PhD}$ thesis. Pretoria: University of Pretoria.

Volk, J. (2001) Publisher's confession. In H. Jenny. Cymatics. Newmarket: Macromedia Publishing.

Wanyama, M. (2006) Music Education: An unexploited goldmine in Kenya. International Journal of Community Music. Selected papers from The Music and Lifelong Learning Symposium. $14^{\text {th }}-16^{\text {th }}$ April 2005. University of Wisconsin-Madison, Wisconsin.

Wentink, C. (2013) "Music teachers should also be musicians": The well-being of general education students teaching music as part of the subject Creative Arts in the Senior Phase. Paper presented at Music and Well-being International Conference, 6 - 10 August 2013, North-West University, Potchefstroom.

Wise, G.W., Hartmann, D.J. \& Fisher. B.J. (1992) Exploration of the relationship between choral singing and successful aging. Psychological Reports. 70. p. 1175-83.

Youtube SA. (2013)How music saved Venezuela's children? [Online] Available at: http://www.youtube.com/watch?v=43tqQhOTCgQ. [Accessed: 28 June 2013].

Youtube SA. (2013) Amazing resonance experiment. [Online] Available at: http://www.youtube.com/watch?v=wvJAgrUBF4w. [Accessed: 28 June 2013].

Zuber-Skerritt, O. (2011) Action leadership: Towards a participatory paradigm. New York: Springer. 